\title{
Activated PI3K-delta syndrome
}

INSERM

\section{Source}

INSERM. (1999). Orphanet: an online rare disease and orphan drug data base. Activated PI3K-delta syndrome. ORPHA:397596

Activated PI3K-delta syndrome is a rare, genetic, primary immunodeficiency disease characterized by increased susceptibility to recurrent and/or severe bacterial and viral infections (in particular, sinopulmonary bacterial and herpesvirus infections), chronic benign lymphoproliferation (manifesting as lympadenopathy, hepatosplenomegaly and focal nodular lymphoid hyperplasia), and/or autoimmune disease (including immune cytopenias, juvenile arthritis, glomerulonephritis and sclerosing cholangitis). Immunophenotypically, variable degrees of agammaglobulinemia with increased IgM levels, increased circulating transitional B cells, decreased naïve CD4 and CD8 T-cells with increased CD8 effector/memory T cells are observed. 